\title{
Diálogos Insurgentes entre Educação Ambiental e Culturas no Encontro Pesquisa em Educação Ambiental (EPEA)
}

\author{
Insurgent Dialogues between Environmental Education and Cultures at the Research in \\ Environmental Education
}

\section{Diálogos Insurgentes entre la Educación Ambiental y las Culturas en la Investigación en Educación Ambiental}

\author{
Marcelo Aranda Stortti ${ }^{1}$ \\ Celso Sánchez Pereira ${ }^{2}$ \\ Laura del Pilar Jiménez Sánchez ${ }^{3}$ \\ Rodrigo da Luz Silva ${ }^{4}$ \\ Rosiléia Oliveira de Almeida ${ }^{5}$ \\ Eliane dos Santos Almeida ${ }^{6}$ \\ Rachel Hidalgo ${ }^{7}$ \\ André Carneiro Melo ${ }^{8}$ \\ Bárbara Pelacani ${ }^{9}$ \\ Carlos Roberto Ferreira ${ }^{10}$
}

\begin{abstract}
Resumo
Este artigo tem por objetivo refletir sobre a temática Educação Ambiental e Culturas, com ênfase nos trabalhos apresentados desde o primeiro Encontro Pesquisa em Educação Ambiental (EPEA), em 2001, até as reflexões ocorridas no Grupo de Discussão de Pesquisas (GDP) desse subcampo de pesquisa, durante o X EPEA, realizado em 2019. Para além de trazer um relato das discussões, o artigo se debruça sobre a evolução das temáticas dos trabalhos relacionados às culturas, apresentados nas quatro primeiras edições do EPEA (2001-2007), em um modesto estado da arte realizado por meio de termos de busca ligados à temática, presentes em seus resumos. Constatamos que, nesse período, as investigações estavam ligadas predominantemente às categorias cultura e saberes, que foram contempladas por trabalhos em todas as edições. Os temas dos Estudos Culturais, Inter/ multiculturalidade e Colonialidade não estiveram presentes nas investigações desse subcampo apresentadas no EPEA, no período, sendo necessário aprofundar a extensão desse fenômeno em revistas e bancos de dissertações e teses, bem como avaliar os desdobramentos epistemológicos e sociopolíticos da atenção que tem sido conferida pelo campo da pesquisa em Educação Ambiental às perspectivas que reconhecem e conferem a voz às diferentes culturas, visando superar os processos de silenciamento que impedem a participação plena nos processos decisórios e na vida social. Temáticas tais que aparecem recentemente no GDP EA e Culturas que valorizam a
\end{abstract}

1 Pesquisador no Grupo de Pesquisa em E.A. Desde el Sur na Universidade Federal do Estado do Rio de Janeiro. E-mail: marcelostortti@gmail.com

2 Professor na Universidade Federal do Estado do Rio de Janeiro. E-mail: celso.sanchez@hotmail.com

3 Mestranda do Programa de Pós-Graduação em Educação da Universidade Estadual Paulista, membro do grupo de pesquisa "Ágora: a temática ambiental e o processo educativo", e do projeto interinstitucional "EArte: Estado da Arte da Pesquisa em Educação Ambiental no Brasil”. E-mail: laura jimesan@hotmail.com

4 Doutorando do Programa de Pós-Graduação em Educação. Faculdade de Educação da Universidade Federal da Bahia. Membro do grupo de pesquisa Interfaces Cultura, Ciência e Ambiente na Educação Crítica. E-mail: rodrigoluz_saj@live.com

5 Professora da Faculdade de Educação da Universidade Federal da Bahia. E-mail: roalmeida@ufba.br

6 Doutoranda em Educação em Ciências na Universidade de Brasília. E-mail: almeida-eliane@hotmail.com

7 Doutoranda em Educação Ambiental do Programa de Pós-Graduação em Educação Ambiental da Universidade Federal do Rio Grande CNPq/PPGEA/FURG. E-mail: rachelhidalgomz@hotmail.com

8 Pesquisador no Grupo RIZOMA na Universidade Estadual de Feira de Santana/BA. E-mail: acmbio@yahoo.com.br

9 Doutoranda em Psicossociologia de Comunidades e Ecologia Social - Universidade Federal do Rio de Janeiro. E-mail: barbara.pelacani@gmail.com

${ }^{10}$ Doutorando em Educação/UFMT. Arte-educador. 
dialogicidade e a inter/multiculturalidade, com críticas à colonialidade e ampliando as possibilidades epistemológicas, político-metodológicas e ontológicas da Pesquisa em Educação Ambiental.

Palavras-chave: Educação Ambiental. Culturas. Pesquisa.

\begin{abstract}
This article aims to reflect on the theme Environmental Education and Cultures with an emphasis on the works presented since the first Research Meeting in Environmental Education in 2001 until the reflections that occurred in the Research Discussion Group of this research subfield, during the X EPEA of the year 2019. In addition to bringing an account of the discussions, the article focuses on the evolution of the themes of works related to cultures, presented in the first four editions of EPEA (2001-2007), in a modest state of art made using search terms related to the theme, present in their abstracts. We found that, during this period, investigations were, predominantly, linked to the categories of culture and knowledge, which were covered by works in all editions. The themes of Cultural Studies, Inter/multiculturality and Coloniality were not present in the investigations of this subfield presented at the EPEA, in the period, being necessary to deepen the extension of this phenomenon in magazines and databases of dissertations and theses, as well as to evaluate the epistemological and sociopolitical developments of the attention that has been given by the field of research in Environmental Education to the perspectives that recognize and give voice to different cultures, aiming to overcome the silencing processes that prevent full participation in decision-making processes and in social life. Such themes have recently appeared in GDP EA and Culturas that value dialogicity and inter/multiculturality, with criticisms of coloniality and expanding the epistemological, political-methodological and ontological possibilities of Environmental Education Research.
\end{abstract}

Keywords: Environmental Education. Cultures. Research.

\title{
Resumen
}

Este artículo tiene como objetivo reflexionar sobre el tema Educación Ambiental y Culturas, con énfasis en los trabajos presentados desde la primera Reunión de Investigación en Educación Ambiental, en 2001, hasta las reflexiones que ocurrieron en el Grupo de Discusión de Investigación de este subcampo de investigación, durante el X EPEA del año 2019. Además de dar cuenta de las discusiones, el artículo se centra en la evolución de los temas de las obras relacionadas con las culturas, presentadas en las primeras cuatro ediciones de EPEA (20012007), en un estado modesto de arte realizado utilizando términos de búsqueda relacionados con el tema, presente en sus resúmenes. Descubrimos que, durante este período, las investigaciones estaban predominantemente vinculadas a las categorías de cultura y conocimiento, que estaban cubiertas por obras en todas las ediciones. Los temas de Estudios Culturales, Inter/multiculturalidad y Colonialidad no estuvieron presentes en las investigaciones de este subcampo presentado en el EPEA, en el período, siendo necesario profundizar la extensión de este fenómeno en revistas y bases de datos de disertaciones y tesis, así como evaluar los desarrollos epistemológicos y sociopolíticos de la atención que ha brindado el campo de la investigación en Educación Ambiental a las perspectivas que reconocen y dan voz a las diferentes culturas, con el objetivo de superar los procesos de silenciamiento que impiden la plena participación en los procesos de toma de decisiones y en la vida social. Tales temas han aparecido recientemente en GDP EA y Culturas que valoran la dialogicidad y la inter/multiculturalidad, con críticas a la colonialidad y ampliando las posibilidades epistemológicas, político-metodológicas y ontológicas de la Investigación en Educación Ambiental.

Palabras clave: Educación Ambiental. Culturas. Investigación.

\section{Introdução}

A voz da minha bisavó ecoou criança nos porões do navio.

Ecoou lamentos de uma infância perdida.

A voz de minha avó ecoou obediência aos brancos donos de tudo.

A voz de minha mãe ecoou baixinho revolta no fundo das cozinhas alheias

de baixo das trouxas roupagens sujas dos brancos

pelo caminho empoeirado rumo à favela.

A minha voz ainda ecoa versos perplexos com rimas de sangue e fome. Conceição Evaristo $^{11}$.

\footnotetext{
${ }^{11}$ Vozes-mulheres. Poemas de recordação e outros movimentos, publicado em 2017.
} 
Este trabalho tem como autores alguns dos participantes do Grupo de Discussão de Pesquisa (GDP) do último Encontro de Pesquisa em Educação Ambiental, ocorrido em Aracaju, em 2019, e que teve como coordenadores os professores Celso Sánchez e Danilo Kato. Neste texto, o coletivo pesquisador analisa os trabalhos apresentados entre 2009 e 2017 nos Encontros de Pesquisa em Educação Ambiental (EPEAs), enfocando a temática das culturas, bem como, no âmbito do Grupo de Discussão de Pesquisas (GDP) Pesquisa em Educação Ambiental e Culturas, no ano de 2019. A opção da escrita coletiva se soma a uma orientação políticoepistemológica afinada com a perspectiva da decolonialidade, procurando exercitar o compartilhamento da autoria e da reflexão coletiva.

Para iniciarmos essa reflexão, buscamos algumas definições de cultura para darmos um suleamento na nossa nau reflexiva, para navegarmos pelos mares revoltos do capitaloceno ${ }^{12}$. A palavra cultura vem do latim colere que significa cuidar, verbo aplicado em distintas situações em que o zelo e o cuidado se fazem necessários, como o cuidado dispensado ao gado, na agricultura ou mesmo aos/as deuses/as nos cultos religiosos.

Com o passar do tempo, essa noção de cultura vinculada ao cuidado deixa de ser a mais usual, e, a partir do Iluminismo, a palavra começa a ser utilizada com um sentido muito próximo ao de civilização, que traz consigo a ideia de civilidade, costumes, vida civil, regras, valores e comportamentos. Nesse período, os/as franceses/as compartilham dessa noção de civilização associada à noção de cultura, que pode ser caracterizada como pertencente ao gênero humano, como o estado do espírito em que se cultiva o conhecimento e a instrução. Ao contrário do universalismo francês, os/as alemães passaram a adotar uma noção de cultura mais particularista, com um viés de exaltação e glorificação de seus costumes, ideias e práticas, de maneira a se diferenciarem e demarcarem sua superioridade em relação a outros povos (CANEDO, 2009).

Essa maneira de entender cultura adquiriu novos aportes quando o termo passou a ser utilizado como critério para se definir o status de uma determinada civilização, seu nível de organização social, que poderia ser medido e comparado com outras civilizações, momento em que a ideia de progresso começou a ser entendida como sinônimo de cultura (CHAUÍ, 2008). Esse entendimento perdurou durante anos, mesmo na pesquisa social, em que os/as antropólogos/as estudavam as diferentes culturas, utilizando como modelo de progresso a Europa, de tal forma que as culturas destoantes desse modelo eram tidas como inferiores, arcaicas, primitivas, ou que ainda não haviam chegado ao nível de organização capitalista esperado.

José Luis dos Santos ressalta a polissemia do termo, o qual tem adquirido sentidos mais amplos ou mais restritivos:

\footnotetext{
Cultura está muito associada a estudo, educação, formação escolar. Por vezes, se fala de cultura para se referir unicamente às manifestações artísticas, como o teatro, a música, a pintura, a escultura. Outras vezes, ao se falar na cultura da nossa época ela é quase que identificada com os meios de comunicação de massa, tais como o rádio, o cinema, a televisão. Ou então cultura diz respeito às festas e cerimônias tradicionais, às lendas e crenças de um povo, ou a seu modo de se vestir, à sua comida, a seu idioma. A lista pode ser ampliada [...]. A primeira concepção de cultura remete a todos os aspectos de uma realidade social; a segunda refere-se mais especificamente ao conhecimento, às ideias e crenças de um povo (SANTOS, 1987, p. 20).
}

12 Segundo Moore (2014), o capitaloceno surge como uma crítica da noção de antropoceno, ao considerar que a ação humana é sempre perpassada por relações políticas e econômicas de poder e desigualdades, no contexto do capitalismo global. O capitaloceno ressalta como as valorizações econômicas capitalistas de apropriação da natureza e de territórios, e não apenas as ações humanas diretas, são a causa das transformações ambientais. 
Cuche (2002, p. 203) explica que o termo cultura pode ser aplicado em diversos "campos semânticos em substituição a outros termos, como 'mentalidade', 'espírito', 'tradição' e 'ideologia". Isso significa extrapolar a ideia de cultura como civilidade e superar a ideia de qualquer forma de hierarquização de culturas. Nesse sentido é que cabe usar a palavra sempre em sua versão plural.

Atualmente, não há como deixar de se destacar a definição de senso comum generalizada nas práticas sociais que associa cultura à detenção ou acumulação de conhecimentos, o que leva à distinção entre pessoas cultas e incultas, que possuem saberes ou que nada sabem. Todavia, a cultura não pode ser reduzida à apropriação de saberes e práticas por determinadas pessoas ou grupos. Ademais, não pode ser reduzida às obras de arte ou a eventos artísticos e de entretenimento, embora essa também seja uma dimensão importante da cultura.

O significado de cultura tem se mostrado extremamente polissêmico nos dias atuais, estando, sempre, associado ao contexto sociopolítico de cada época e à organização social devido à plasticidade do conceito e às suas variadas aplicações nos mais diversos campos do conhecimento. A palavra tem recebido diversas adjetivações, "cultura popular" (BRANDÃO, 2000, p. 386), “cultura política” (CHAUÍ, 2000, p. 71), "cultura ecológica” (LEFF, 2009,p. 37) e a "cultura para a sustentabilidade ambiental" (FEITOSA, 2016, p.55), existindo distintos conceitos de cultura, no plural, em voga na contemporaneidade.

Existe uma relação intrínseca entre a linguagem e a cultura, que começou a ser caracterizada no século XIX. Essa relação é demasiadamente estreita e complexa, pelo fato de que é por meio das palavras que um/a indivíduo/a acessa a cultura, mas essas palavras também são elementos culturais. De um lado, a linguagem parece ser o fundamento que receberá a estrutura formada por elementos culturais, mas, de outra perspectiva, um desses elementos culturais é sobretudo a própria língua por meio da qual os/as sujeitos/as acessam a cultura do grupo ao qual pertencem. Nesse sentido, a língua pode ser entendida como um sistema de comunicação que, ao mesmo tempo que forma a cultura, é também formada por ela (CUCHE, 2002). Essa articulação se relaciona com o sistema de significações que gira em torno das criações humanas: a singular habilidade dos/as seres humanos/as em relacionar-se com o ausente por meio de símbolos e de trazer à existência o que ainda não existe (CHAUÍ, 2008).

Geertz (1989, p. 15) dialoga com essa ideia quando afirma que "o homem é um animal amarrado a teias de significados que ele mesmo teceu, assumo a cultura como sendo essas teias e a sua análise [...] a cultura é a mediação entre o poder e o objetivo de sua ação". Diferentemente do animal irracional, o/a ser humano/a não exibe uma simples aderência ao suporte da vida, não se mostra biologicamente ligado à natureza para, simplesmente, a ela se adaptar, senão para transformá-la, o que evidencia os laços existentes entre natureza e cultura. Em outras palavras, Freire (1987, p. 40-41) diz o mesmo quando explica que "não há mundo sem o homem", ainda que existam as árvores, os mares e as estrelas, é preciso de um/a ser humano/a que diga: "Isto é mundo".

Nesse sentido, a cultura é a significação das atividades humanas que se estabelece na relação ser humano/a-natureza. Está intimamente relacionada com o processo de humanização, que ocorre por meio do trabalho, ato fundante da humanidade por meio do qual, ao se relacionar com a natureza, os/as sujeitos/as objetivam uma série de bens culturais, os quais, surgindo da realidade concreta, a ela retornam repletos de significação. Freire (1983, p. 14), reitera a relação entre natureza e cultura quando afirma que "não é possível, portanto, entender as relações dos homens com a natureza, sem estudar os condicionamentos histórico-culturais a que estão submetidas suas formas de atuar", algo que demarca a necessidade de análise crítica contextualizada quando se trata do assunto.

A cultura, como uma dimensão da realidade que está na essência ontológica do/a ser humano/a, e que se expressa em sua capacidade de criar, inventar, atuar politicamente e 
transformar, ao mesmo tempo em que serve à humanização, pode tornar-se puro ato desumanizador que coloca o/a sujeito/a criador/a na posição de coisa criada, situação alienante que ocorre, demasiadamente, no âmbito das sociedades capitalistas contemporâneas.

De igual forma, essa noção ampliada de cultura, entendida como algo próprio de todo/a ser humano/a enquanto sujeito/a cultural, não ocorre da mesma maneira em sociedades divididas em classes. Nesse tipo de organização social, em que o trabalho, que deveria ser o ato fundante da humanidade, se torna pura alienação capitalista, os/as seres humanos/as são impedidos/as de alcançar suas potencialidades, são tolhidos em sua criatividade e na capacidade que têm de transformar; são desconsiderados/as em sua cultura. No jogo da dominação e da opressão não existe o respeito entre culturas diferentes, mas predomina a assimilação cultural na busca pelo prestígio, legitimidade e domínio das estruturas sociais, compreensão que amplia o conceito de cultura colocando-o próximo ao de campo social.

Assim também colocou Freire (1987), ao argumentar sobre as relações de ensinoaprendizagem revolucionárias. Para o autor, a relação interpessoal que se dá entre educador/a e educando/a se efetiva não somente na inserção do/a aluno/a na cultura das sociedades, ou seja, na inserção daquele/a em determinado mercado de trabalho ou em condições de seguir regras estabelecidas, mas, sim, facilitando a "temporalização do espaço" - o que significa ser capaz de historicizar as informações epocais e enxergá-las no contexto (FREIRE, 1987, p. 47).

Antonio Gramsci (1982) também estava preocupado com a influência da cultura no processo revolucionário e na sociedade, pois tinha clareza da importância da organização da cultura das classes populares como ato revolucionário na direção da construção de sociedades não desiguais. Nessa perspectiva, o autor descortina os interesses sociais de grupos hegemônicos presentes na sociedade, que utilizam da força estatal como mecanismo de repressão das classes populares, no sentido de manter seus privilégios. A partir dessa organização da cultura, Gramsci investigou o papel de certos grupos sociais, identificando-os como:

[...] dois grandes "planos" superestruturais: o que pode ser chamado de "sociedade civil" (isto é; o conjunto de organismos chamados comumente de "privados") e o da "sociedade política ou Estado", que correspondem à função de "hegemonia" que o grupo dominante exerce em toda a sociedade e àquela de domínio direto" ou de comando, que se expressa no Estado e no governo "jurídico" (GRAMSCI, 1982, p. 11 , grifo nosso).

Como podemos observar, Gramsci (1982, p. 11) explica que a "sociedade política ou Estado" apresenta um poder hegemônico em relação à sociedade civil, isto é, cria regras e normas que têm que ser seguidas por todos/as. Para que esses preceitos sejam seguidos, o autor explica que esse grupo social apresenta uma hegemonia cultural, entendendo hegemonia como a construção de uma mentalidade uniforme baseada no consentimento.

A intenção da burguesia é conquistar e manter o domínio e direção das demais frações sociais, e, para isso, não poderá fazer uso apenas da força, mas precisará exercer liderança moral e intelectual. Essas lideranças se efetivam mediante o uso de todos os instrumentos de domínio que a burguesia tem a seu serviço: mídias televisivas, rádios, propagandas publicitárias, bens de consumo, escolas e toda a indústria cultural que, de forma inconsciente, vai direcionando, realinhando os desejos, vontades, medos e interesses das classes sociais dominadas para que consintam com a dominação.

Aprofundando o pensamento Gramsciano, Bezerra (2016, p. 2) afirma que Gramsci se preocupava desde cedo com o que, mais tarde, denominaria de "organização da cultura", ou seja, com os organismos construídos, no interior de uma sociedade, com a função ideológica de difundir uma determinada cultura. 
Gramsci, ao associar o significado de cultura ao exercício do pensamento, um atributo de todas as pessoas, expressa, de forma propositiva, como concebe o vínculo entre o pensamento orgânico e a organização da cultura no processo revolucionário e na sociedade:

[...] exercício do pensamento, aquisição de ideias gerais, hábito de conectar causas e efeitos. Para mim, todos já são cultos, porque todos pensam, todos conectam causas e efeitos. Mas o são empiricamente [...] não organicamente. E assim como sei que a cultura é também um conceito basilar do socialismo, porque integra e concretiza o vago conceito de liberdade do pensamento, assim gostaria também que ele fosse vivificado por outro. Pelo de organização. Organizemos a cultura, assim como buscamos organizar toda a atividade prática (GRAMSCI, 1917 apud DIAS, 2000, p. 68).

O termo indústria cultural remete ao sistema formado por instrumentos, que, segundo Horkheimer e Adorno (1985, p. 111), conferem a tudo "um ar de semelhança" na cultura contemporânea, criando a falsa ideia de identidade entre indivíduos/as e de existência de um todo social, retratado nos meios de comunicação. Nesse caso, "até mesmo as manifestações estéticas de tendências políticas opostas entoam o mesmo louvor do ritmo de aço". Essa indústria passa, então, a constituir a já citada hegemonia, capaz de silenciar aqueles/as que não se encaixam e não se submetem aos seus padrões de produção.

Em diálogo com esse pensamento de disputa de poder, construção de hegemonia cultural e busca de sua superação, Paulo Freire e Donaldo Macedo, conversando sobre esse tema e o processo de alfabetização, chamam a atenção para a presença de muitas definições de cultura e explicam que eles não estão falando da cultura com " C' maiúsculo", aquela pregada pelas elites econômicas, mas que se referem a uma concepção de cultura como um "sistema caracterizado por estratificação e tensões sociais" (FREIRE; MACEDO, 1990, p. 33). A partir das reflexões sobre o processo de opressão e libertação dos/as oprimidos/as Paulo Freire cria o conceito de invasão cultural que

[...] sugere, obviamente, um sujeito que invade. Seu espaço histórico-cultural, que lhe dá sua visão de mundo, é o espaço de onde ele parte para penetrar outro espaço histórico-cultural, superpondo aos indivíduos deste seu sistema de valores (FREIRE, 1983, p. 26).

Logo, para esse autor, esse processo é totalmente alienante, sendo uma violência completa que pode ameaçar ou destruir a criatividade e originalidade cultural dos/as que sofrem a invasão/opressão. Nesse processo podemos observar uma dupla face: a "dominação" e a "tática da dominação" (FREIRE, 1987, p. 149). O/a invasor/a na maioria das vezes constrói um discurso que parece predispondo a socorrer, que vai ajudar os/as mais desvalidos/as, porém, no fundo, o seu interesse é dominar os/as condenados/as da Terra (FANON, 2000). Os/as opressores/as querem adestrar e modelar os/as oprimidos/as a "seus padrões" e a seus "modos de vida" (FREIRE, 1987, p. 150) e para tal buscam conhecer o mundo dos/as invadidos/as, para que possam olhar para a sua realidade através das grandes narrativas construídas pelos/as invasores/as.

Para que os/as opressores/as tenham êxito na sua conquista, faz-se necessária a construção de uma identidade de subalternidade e de mediocridade. A partir dessa forma de se enxergar no mundo, os/as oprimidos/as se submetem aos valores dos/as opressores/as, o que aumenta a alienação desses/as sujeitos/as outrora históricos/as, que foram subsumidos/as, subjugados/as e expropriados/as da sua própria cultura, através de um processo que Dussel (1992, p. 11) chama de "encobrimento do outro". 
Freire (1987, p. 151) explica que o eu social dos invadidos/as /oprimidos/as se constitui nas "relações socioculturais" que estão na "estrutura" e que, nesse processo, eles/as querem ser iguais aos/as invasores/as, no seu jeito de se relacionar com a estrutura social e com os/as outros/as humanos/as e a natureza. Além disso, toda a sociedade dominada pela opressão apresenta essa estruturação também.

Esse pensamento relacionado a um poder central que impõe o seu projeto hegemônico, nesse caso, imperialista, também está presente na obra de Edward Said, que entende a cultura como:

[...] todas aquelas práticas, como as artes de descrição, comunicação e representação, que têm relativa autonomia perante os campos econômico, social e político, e que amiúde existem sob formas estéticas, sendo o prazer um de seus principais objetivos (SAID, 2011, p. 4).

Nos campos de pesquisa, o conceito de cultura também apresenta significações diversas e está intrinsecamente relacionado com as epistemologias e referenciais teóricos abordados nas investigações que dialogam com as culturas. Nesse sentido, quando falamos em cultura, tornase necessário explicitar de qual lugar estamos falando e que conceitos mobilizamos ao tratar do assunto.

\section{Os diálogos entre Educação Ambiental e Culturas nos EPEAs}

Para dar continuidade às reflexões apresentadas por outros/as autores/as, como Guido (2013), Carvalho e Schmidt (2008), Rink e Megid Neto (2009) e Guerra e Guimarães (2007), nesta pesquisa fizemos uma análise dos trabalhos enviados para os EPEAs de 2001 a 2007, pois de 2009 a 2017 os trabalhos foram analisados por Fernandes et al. (2018).

A metodologia utilizada para a investigação foi embasada na pesquisa Estado da Arte (FERREIRA, 2002) e para analisar tematicamente os resumos e artigos utilizamos a análise de conteúdo, na perspectiva de Bardin (1978), buscando, nos resumos dos trabalhos aprovados e apresentados nesse evento, os seguintes termos de busca, identificados nas discussões do GDP, que foram utilizadas por Fernandes et al. $(2018$, p. 6):

[...] cultura; estudos culturais; discurso; comunicação; identidade; interculturalidade; multicultural (multiculturalidade, multiculturalismo); colonial (colonialidade, póscolonial, pós-colonialismo, decolonialidade); saberes.

Após as análises flutuantes dos trabalhos do EPEA, alguns deles não estavam realmente apresentando contribuições para o subtema da cultura, por esse motivo os mesmos foram descartados do corpo da investigação.

Assim, apresentamos nossos resultados na Tabela 1, expressos em número de trabalhos por edição do EPEA, organizados para os diversos termos de busca. A tabela mostra os trabalhos que entendemos pertencer ao escopo do GDP. 
Tabela 1 - Pesquisas relacionadas à cultura, identificadas nos anais do evento por ano de realização

\begin{tabular}{|c|c|c|c|c|c|c|c|c|}
\hline & \multicolumn{9}{|c|}{ Temas } \\
\hline $\begin{array}{c}\text { Edições do } \\
\text { Epea }\end{array}$ & Cultura & $\begin{array}{c}\text { estudos } \\
\text { culturais }\end{array}$ & Discurso & comunicação & identidade & $\begin{array}{c}\text { Inter/multi } \\
\text { cultural }\end{array}$ & colonial & saberes \\
\hline 2001 & 3 & 0 & 0 & 0 & 0 & 0 & 0 & 2 \\
\hline 2003 & $1^{*}$ & 0 & 1 & 0 & $1^{*}$ & 0 & 0 & 1 \\
\hline 2005 & 1 & 0 & 0 & $1^{*}$ & $1^{*}$ & 0 & 0 & 1 \\
\hline 2007 & 1 & 0 & 2 & 1 & 0 & 0 & 0 & 1 \\
\hline * trabalhos que apresentaram as duas temáticas ao mesmo tempo.
\end{tabular}

Fonte: os autores

Ao observarmos os termos levantados nos anais do EPEA, podemos destacar que nesse período de 2001 a 2007 as investigações estavam ligadas, predominantemente, às categorias: saberes e cultura, pois estiveram presentes em todas as edições.

O tema discurso apresentou três trabalhos, com a seguinte distribuição: um trabalho no ano de 2003 e dois em 2007. Os temas comunicação e identidade foram contemplados com duas pesquisas cada um no total. Os temas dos Estudos Culturais, Inter e multicultural e Colonial, nesse período, não estiveram presentes nas investigações desse subcampo, sendo necessário aprofundar as investigações analisando revistas e bancos de dissertações e teses para detalhar essa questão.

Carvalho e Schmidt (2008) investigaram as questões temáticas apresentadas em eventos científicos em EA, como a Associação Nacional de Pós-Graduação e Pesquisa em Educação (ANPED), Associação Nacional de Pós-Graduação e Pesquisa em Ambiente e Sociedade (ANPPAS) e o EPEA no período de 2001 a 2006. A partir dessa pesquisa sobre a temática cultura, foram identificados dezessete trabalhos encaminhados pelos/as participantes no EPEA. Desse total, seis trabalhos foram apresentados em 2001; quatro em 2003 e sete em 2005.

A diferença entre os números de trabalhos apresentados no levantamento feito por esses/as pesquisadores/as e neste trabalho, descritos na Tabela 1, pode estar relacionada com a diferença metodológica proposta em cada pesquisa, pois foram escolhidas categorias temáticas mais amplas, não seguindo a divisão do próprio evento, bem como um detalhamento pouco aprofundado sobre o que seria cada categoria temática, sendo determinada apenas a expressão EA na cultura que pode envolver um espectro mais amplo desse conceito e, consequentemente, englobar artigos que na nossa pesquisa estão em outros GDPs e, por isso, não foram relacionados, como por exemplo aqueles relacionados à cultura escolar.

Nesse período (2001-2007), os temas que não apareceram ou foram pouco recorrentes não determinam a ausência da necessidade de se investigar essas temáticas, sua irrelevância ou que não existam grupos de pesquisa e pesquisadores/as debatendo esses temas em outros espaços acadêmicos.

Para reforçarmos essa observação, analisamos o site do Diretório de Grupos de Pesquisa do CNPQ e encontramos 23 grupos de pesquisas utilizando os descritores educação ambiental e cultura, que apresentam propostas de pesquisas pertinazes há muitos anos. A partir disso, corroborando com Carvalho e Schmidt (2008, p. 169) podemos pensar que "a menor evidência dessas temáticas como indicativo do caráter emergente do diálogo das suas áreas de origem - a psicologia social de abordagem sócio-histórica e os estudos culturais - com a educação ambiental".

Complementando essa investigação Fernandes et al. (2018), analisaram os EPEA de 2009 a 2013, observando uma quantidade maior de pesquisas que apresentaram as categorias intercultural e identidade, reforçando a ideia de Carvalho e Schmidt (2008) sobre a emergência desses temas. Porém, esse aumento de pesquisas nessas temáticas não continuou no ano de 2015, o que constatamos não ter representatividade também nos eventos de 2001 a 2007. 
A presença dessas temáticas voltou a crescer na edição de 2017 do evento, pois identificou-se uma frequência relativamente alta, quando comparado aos outros termos no mesmo período. Há ainda o termo colonial com presença significativa, principalmente nos dois últimos eventos. O termo saberes também aparece somente a partir de 2011, sendo ausente no evento anterior de 2009, porém esteve presente nos encontros de 2001 a 2007.

A partir dos dados anteriormente apresentados, podemos supor que a EA, como um campo jovem, se permite a diversos diálogos epistemológicos, bem como com outras áreas e referenciais teóricos.

Hart e Nolan (1999) evidenciaram essa permeabilidade, ao observarem que o campo da Educação Ambiental se tornou mais complexo desde a década de 1990, apresentando pesquisas com diversos referenciais, ampliando o debate sobre métodos, epistemologias e fundamentos ontológicos.

Carvalho e Schmidt (2008) afirmam que a EA é um campo de pesquisa permeável aos desdobramentos epistemológicos de outros campos como, por exemplo, o campo dos estudos culturais, incorporando, assim, paulatinamente, as temáticas e os debates em torno da problematização do multiculturalismo e da proposta da interculturalidade, em particular dos aportes do chamado giro decolonial, que começaram a ser incorporados nos trabalhos em educação ambiental, mais recentemente. Dentre esses movimentos, Carvalho (2015) evidenciou o crescimento de pesquisas que tendem a ouvir outras vozes, que não eram foco das produções acadêmicas na década de 1980 .

Loureiro (2004) destaca, também, dimensões que têm sido relegadas ao esquecimento, e que passam a ser incorporadas ao se considerar a dinâmica em que se situa a Educação Ambiental:

\footnotetext{
Educação ambiental é uma perspectiva que se inscreve e se dinamiza na própria educação, formada nas relações estabelecidas entre as múltiplas tendências pedagógicas e do ambientalismo, que têm no "ambiente" e na "natureza" categorias centrais e identitárias. Neste posicionamento, a adjetivação "ambiental" se justifica tão somente à medida que serve para destacar dimensões "esquecidas" historicamente pelo fazer educativo, no que se refere ao entendimento da vida e da natureza, e para revelar ou denunciar as dicotomias da modernidade capitalista e do paradigma analítico-linear, não-dialético, que separa: atividade econômica, ou outra, da totalidade social; sociedade e natureza; mente e corpo; matéria e espírito, razão e emoção etc. (LOUREIRO, 2004, p. 66).
}

A partir da análise dos trabalhos apresentados durante os dezoito anos desse encontro nacional de pesquisa em diálogo com a temática das culturas, faz-se necessário expandirmos esse horizonte de investigação e mergulharmos nos inéditos viáveis, como Paulo falava, isto é, aquela "crença no sonho possível e na utopia que virá" e que "o problema não é mais um sonho, que ele pode se tornar realidade" (FREIRE, 2011, p. 276) que pesquisadores/as trazem para o espaço da arena pública do GDP Educação Ambiental e Culturas.

\section{O GDP em Educação Ambiental e Culturas no X EPEA (2019)}

No VII EPEA, no ano de 2013, em Rio Claro/SP, foi realizado, pela primeira vez, o Grupo de Pesquisa em Educação Ambiental e Culturas. Sob a coordenação da professora Lúcia de Fátima Estevinho Guido, o GDP recebeu oito trabalhos que tratavam das seguintes temáticas: fotografia, mídia, cultura e arte, contando com a presença de, aproximadamente, quinze participantes (FERNANDES et al., 2018, p. 156). E, segundo Lucia de Fátima Estevinho Guido, o GDP EA e Culturas 
[...] tem a preocupação de reunir as pesquisas que fazem interlocução com a cultura e seus processos de produção nos museus, nas artes visuais, nos cotidianos, nas mídias, na fotografia, na literatura, no cinema e nas intervenções artísticas a partir de diferentes campos teóricos como os estudos culturais; as perspectivas pósestruturalistas; pós-modernas e as filosofias da diferença (GUIDO, 2013, s/p).

O GDP em Educação Ambiental e Culturas do X EPEA ocorreu como um processo esclarecedor e autêntico de formação, que se propunha a fazer brotar das grietas as resistências, os saberes outros, as insurgências, como forma de transgressão de um padrão eurocentrado imposto a todos/as de maneira indistinta com evidente pretensão de universalidade. Dessas fissuras nascem as práxis genuinamente transformadoras, a ação reflexiva e esperançosa na busca da construção de relações menos conflituosas entre ser humano/a-natureza, de outras formas de ser e estar no mundo, como afirma Catherine Walsh:

[...] aprender a pensar y actuar en sus afueras, fisuras y grietas, donde moran, brotan y crecen los modos-otros, las esperanzas pequeñas. Las grietas se han convertido en parte de mi localización y lugar. Son parte integral de cómo y dónde me posiciono política, epistémica, ética estratégicamente. Son parte integral también de las transgresiones, indisciplinamientos, rupturas y desplazamientos que me obligan a mirarme críticamente, a aprender a desaprender para reaprender a pensar, actuar, sentir y caminar decolonialmente, a nivel individual y en colectividad (WALSH, 2017, p. 31).

As discussões do GDP levaram a reflexões acerca da necessidade do devido reconhecimento dos lugares que os/as sujeitos/as ocupam no mundo, mas também da problematização dos discursos construídos sobre eles/as, da invisibilização desses lugares, desses/as sujeitos/as e de suas experiências por grupos detentores do poder. A ação segregadora e alienante proveniente da relação de dominação - classista, sexista e racista - aí existente se pauta em atitudes discriminatórias que visam a inferiorização e o apagamento da cultura das classes populares, das mulheres, do grupo LGBTQI, do povo preto e do povo indígena. Todas perspectivas que apontam para a necessidade da educação ambiental ser capaz de apontar para outras direções, em particular para o diálogo com estes sujeitos muitas vezes invisibilizados ou colocados em condição de subalternidade (KASSIADOU; STORTTI; SÁNCHEZ, 2018; KASSIADOU; STORTTI; SANCHEZ, 2016)

Os trabalhos desenvolvidos no GDP (Quadro 2) possibilitaram evidenciar a riqueza que existe na diferença, entendida como a dimensão fundamental das sociedades presentes no mundo. Possibilitaram, ainda, reconhecer a incrível multiplicidade de ambientes integrados à teia da biodiversidade e da pluralidade cultural, de tal forma que entender a diferença como um problema a ser solucionado seria cometer um atentado à diversidade e à beleza da vida.

\begin{tabular}{|l|l|l|}
\hline \multicolumn{1}{|c|}{ Título } & \multicolumn{1}{c|}{ Autores } & \multicolumn{1}{c|}{ Palavras-chave } \\
\hline A educação ambiental na umbanda & Katia Gonçalves Castor & $\begin{array}{l}\text { Racionalidade, povos de } \\
\text { terreiros, complexidade; } \\
\text { cooperação; comunitarismo. }\end{array}$ \\
\hline $\begin{array}{l}\text { Educação ambiental, identidades e ecologias: os } \\
\text { processos globalizadores em uma biorregião }\end{array}$ & Flávia Nascimento Ribeiro & $\begin{array}{l}\text { Biorregionalismo, sujeitos } \\
\text { engajados, tessituras da } \\
\text { Educação Ambiental. }\end{array}$ \\
\hline $\begin{array}{l}\text { Se acabar o rio, a comunidade acaba": saberes e } \\
\text { vivências que intercruzam os sujeitos e a biodiversidade } \\
\text { em um território quilombola do semiárido baiano }\end{array}$ & $\begin{array}{l}\text { André Carneiro Melo, } \\
\text { Marco Antonio Leandro } \\
\text { Barzano, Marta Pereira de } \\
\text { Almeida e Dilza Bispo } \\
\text { Bastos }\end{array}$ & $\begin{array}{l}\text { Territorial, comunidade } \\
\text { quilombola, decolonial, } \\
\text { biodiversidade, produção } \\
\text { cultural dos territórios, } \\
\text { memórias bioculturais. }\end{array}$ \\
\hline
\end{tabular}

Quadro 2 - Título dos trabalhos, autores/as e palavras-principais das pesquisas 
A partir do quadro acima podemos observar a presença de grupos sociais específicos, como Quilombolas, Caiçaras e Povos de Terreiros, que estão sendo investigados e tendo seus saberes e fazeres descortinados e desvelados para o público através de suas/seus autoras/es. Além disso, as/os autoras/es acima buscam promover diálogos sobre a práxis desses sujeitos sociais e as reflexões e ações da educação ambiental.

Outra questão que podemos destacar foi a ressignificação do pensamento sobre a biodiversidade, presente em quase todos esses trabalhos, bem como a importância de um outro tipo de diálogo com os/as seres vivos/as e com as práticas sociais outras, desenvolvidas pelos coletivos humanos. Essa ressignificação pode ter ocorrido em diálogo com o desenvolvimento de outras práticas sociais que buscaram outras formas de pensar e agir para além do capital, construindo uma relação de menos exploração e mais convivência com os/as outros/as seres vivos/as e uma outra relação com os elementos da natureza, como a água, que não é vista como um recurso natural, mais um ser maior da espiritualidade de cada um/a desses/as sujeitos/as.

Para ressignificar o conceito de biodiversidade na ruptura com a colonialidade, Melo (2019) defende a possibilidade de entender a biodiversidade somada a uma produção cultural regional dos territórios, valorizando a cultura material e imaterial das comunidades locais e que, sobretudo, busque criar empatia com os modos de viver dessas comunidades, demostrando que a biodiversidade não é apenas um produto da natureza, mas é, também, produto da ação das sociedades e culturas humanas, em particular, das sociedades tradicionais.

A partir dessas experiências de viver e estar em territórios com áreas naturais onde algumas inclusive são Unidades de Conservação, foi possível, nessas pesquisas, identificar certas práticas sociais que geram contribuições importantes para preservar e manter o meio ambiente local e todas as formas de vida. Esses saberes e práticas podem servir de guia não só para aqueles que se reconhecem enquanto parte dessas culturas, mas para superarmos a crise planetária - social, ambiental, política, econômica, cultural - que enfrentamos enquanto humanidade. Essa crise é consequência direta do esquecimento daqueles saberes e sabedorias cultivadas pelas culturas ancestrais através dos quais se tornou possível a nossa sobrevivência no planeta.

A dialogicidade, numa perspectiva freireana, apresenta-se como a marca do GDP sobre Educação Ambiental e Culturas do EPEA, pois se caracteriza pela postura ética de ouvir/escutar as diferentes culturas ali presentes e representadas, no sentido de ir na contramão da cultura do silêncio, fazendo aparecer grupos historicamente excluídos dos processos decisórios e da vida social.

Para Boaventura de Sousa Santos, a invisibilização de uma cultura por outra, própria do processo político autoritário e vertical, está intimamente relacionada ao conceito de linha abissal, isto é, linhas imaginárias que estabelecem distinções entre as pessoas e os diferentes grupos culturais (SANTOS, 2007). Para o autor, o paradigma da racionalidade ocidental presente desse lado da linha se firmou a partir da negação e do apagamento dos saberes presentes do outro lado da linha, que foram tidos como inferiores, mitológicos e desnecessários à concepção de conhecimento válido apregoado. O paradigma da racionalidade ocidental, presente desse lado da linha apresenta uma base institucional sólida, visto que é demandado por diferentes sujeitos/as, empresas, organizações neoliberais, universidades etc., e se baseia no paradigma da regulação/emancipação. Exatamente com o intuito de romper com essa linha abissal, que o GDP se apresenta como território de encontro.

Desse lado da linha não há possibilidade de coexistência com o outro lado da linha, aliás, nisso se baseia sua continuidade. Do outro lado da linha existem saberes outros, sementes sufocadas, negligenciadas e esquecidas, porque não condizentes com o paradigma dominante. A colonialidade foi construída a partir do paradigma da apropriação/violência, em que os povos 
colonizados sofreram processos constantes de desumanização. Eles não tiveram suas necessidades mais básicas atendidas e, devido a isso, seus problemas permaneceram ao longo do tempo intactos, necessitando ser considerados, pelas agendas de pesquisa, como demandas válidas e legítimas. É nessa frente que esse GDP se insere, organizando, reunindo e incentivando pesquisas que contribuam para preencher a lacuna histórica de trabalhos que articulem Educação Ambiental e Culturas.

Em diálogo constante no GDP, consideramos o contexto latino-americano e a situação de opressão a que historicamente se situam, sobretudo, negros/as, indígenas, quilombolas, LGBT's, mulheres, dentre outros grupos, problematizando essa realidade e refletindo sobre ela para transformá-la. Certamente, do outro lado da linha existem insurgências e o que Santos (2007) denomina de patrimônio comum da humanidade, que são formas de enfrentamento do paradigma dominante pautado em globalismos localizados e em localismos globalizados, na direção da construção de realidades culturalmente sensíveis que considerem a ecologia dos saberes. Tal ecologia deverá ser pautada no pluralismo cultural e, portanto, na valorização de todas as formas culturais, balizada no princípio da hermenêutica diatópica, que, por sua vez, se refere a processos culturais que ocorrem com um pé numa cultura e outro em outra cultura. Só assim será possível aumentar ao máximo a noção de incompletude cultural, necessária para a percepção da riqueza que existe nas diferentes culturas presentes no mundo (SANTOS, 2007).

\section{Considerações finais}

Uma das nossas intenções com este artigo foi iniciar um monitoramento reflexivo do perfil dos trabalhos apresentados no principal evento de pesquisa em EA no Brasil, o EPEA, oferecendo subsídios para que outros/as pesquisadores/as possam retomar esses achados e mesmo lançar outras hipóteses além das aqui levantadas para a compreensão da integração Educação Ambiental e Culturas.

Reconhecemos a necessidade de continuar observando e analisando tais eventos e de criar uma série histórica. O que nos ajudará a ver, no decorrer de um tempo mais amplo, mudanças e tendências no perfil de pesquisadores/as e trabalhos do campo, bem como a avaliar possíveis relações entre as direções das pesquisas e as políticas públicas de educação, meio ambiente e cultura.

Ademais, necessário e oportuno refletirmos, no contexto da EA, em especial nessa arena pública, os direcionamentos promulgados a favor dessa temática que estejam em contínuo abraço com a arte. No sentido de que haja um outro olhar sobre o conjunto das epistemologias emergentes para o tempo presente, apresentadas no X EPEA. Ainda, deflagrar uma EA que não só abrace a arte com todos os seus braços culturais, mas que, rizomatize-se num diálogo profundo, resgatando uma América latina outra, como diria Paulo, não com $A$ maiúsculo da palavra arte, relacionada as tradições hegemônicas silenciadoras das artes subalternas e subversivas, mas pensar arte em seu ambiente cultural, de dentro para fora, pelas frestas e quebradas das ruas e nos recôncavos dos guetos emergindo e tocando fogo nos canaviais contemporâneos.

Essa temática conviveu, nesses anos e em especial no último EPEA, numa praxiologia de arena, num picadeiro sociopolítico e cultural. Assim, a EA rebela-se insurgente! Portanto, debandemos em matilhas! Arribamos à caça dos espaços vazios e das ausências de políticas públicas, no atual momento em que vivemos no Brasil e em outros países da América Latina, buscando preenchê-los do verde esperança da ética e da política nos encontros de pesquisa em educação e para além deles, cuja axiologia contemple projetos socioambientais populares e que propicie a ocupação de outros espaços públicos, interligue e "favoreça a relação escolacomunidade" (LOUREIRO; COSSÍO, 2007.), resgatando no imaginário das comunidades o 
projeto libertador da educação popular, nas trilhas do inédito viável de uma arte-educaçãoambiental outra.

O GDP EA e Culturas tem em sua marca a dialogicidade, como um espaço de escuta e visibilização de saberes, um encontro que visa preencher lacunas históricas. Identificamos a necessidade de expansão dos horizontes de investigação da EA, com mergulhos mais profundos nos inéditos viáveis. Nesse sentido, o GDP em Educação Ambiental e Culturas do X EPEA apareceu como um território fértil para criação e reconhecimento das grietas e resistências, que vêm se constituindo e fortalecendo ao longo das últimas décadas no estímulo às práxis transformadoras no campo de pesquisa da EA. Nos trabalhos apresentados em 2019, a inter/multiculturalidade e o diálogo de saberes trazem questões culturais dos/as oprimidos/as, contribuindo para aprofundar os debates epistemológicos, metodológicos e ontológicos, na busca de uma identidade própria da EA.

Percebemos, através do presente estudo, o histórico de ocupação do GDP e seus formatos e temas de pesquisa vêm se diversificando. As temáticas iniciais estavam relacionadas às ferramentas e aos processos, como: fotografia e mídia, e agora caminha a passos largos na abordagem de reflexões crítico-culturais e rupturas epistemológicas. Parte de transgressões e rupturas, onde percebemos que as discussões do GDP levaram a reflexões acerca da opressão dos/as sujeitos/as pelos grupos detentores de poder. A compreensão da colonialidade dentro do campo de Educação Ambiental e Cultura levou à problematização da condição dos sujeitos oprimidos, sendo possível que, futuramente, o debate de gênero, classe e raça se amplie.

\section{Referências}

BARDIN L.. Análise de Conteúdos. Lisboa: Edições 70. 1978.

BEZERRA, C. S. A construção da concepção de cultura em Antonio Gramsci: uma análise da produção pré-cárcere. In: JORNADA INTERNACIONAL DE ESTUDOS E PESQUISAS EM ANTONIO GRAMSCI, 1, 2016, Fortaleza. Anais... Fortaleza: Universidade Federal do Ceará, 2016. p. 1-15. Disponível em: http://www.ggramsci.faced.ufc.br/wp-content/uploads/2017/06/A-CONSTRU__ ODA-CONCEP__ O-DE-CULTURA-EM-ANTONIO-GRAMSCI-UMA-AN_LISE-DAPRODU___ O-PR__C_RCERE.pdf. Acessado em 17 de maio de 2017.

BRANDÃO, C. R.. A educação como cultura. Memórias dos anos sessenta. Horizontes Antropológicos, Porto Alegre, ano 23, n. 49, p. 377-407, set./dez. 2017. Disponível em: https://www.scielo.br/pdf/ha/v23n49/0104-7183-ha-23-49-00377.pdf. Acessado em 04 de março de 2018.

CANEDO, D. P. Cultura é o quê?: reflexões sobre o conceito de cultura e a atuação dos poderes públicos. In: ENCONTRO DE ESTUDOS MULTIDISCIPLINARES EM CULTURA - ENECULT, 5, 2009, Salvador. Anais... Salvador: Universidade Federal da Bahia, 2009. p. 1-15. Disponível em: http://www.cult.ufba.br/enecult2009/19353.pdf. Acessado em 29 de maio de 2017.

CARVALHO, I. C. de M.; SCHMIDT, L. S. A pesquisa em Educação Ambiental: uma análise dos trabalhos apresentados na ANPED, ANPPAS e EPEA de 2001 a 2006. Pesquisa em Educação Ambiental, Rio Claro, v. 3, n. 2, p. 147-174, 2008.

CARVAlHO, L. M. Pesquisa em Educação Ambiental no Brasil: um campo em construção? 2015. p. 349. Tese (Livre Docência em Educação Ambiental - disciplina: Educação Ambiental e Práticas Pedagógicas) - Departamento de Educação, Instituto de Biociências, Universidade Estadual Paulista, Rio Claro, 2015.

CHAUÍ, M. S. Cultura política e política cultural. Estudos Avançados, 9 (23). 1995. 
CHAUÍ, M. S. Cultura e democracia. Crítica y Emancipación: Revista latinoamnericana de Ciencias Sociales. Buenos Aires, Ano 1, n 1, p. 53-76, 2008. Disponível em: http://bibliotecavirtual.clacso.org.ar/ar/libros/secret/CyE/cye3S2a.pdf. Acessado em: 07 de maio de 2017.

CUCHE, D. O conceito de cultura nas Ciências Sociais. Tradução de Viviane Ribeiro. 2 ed. Bauru: EDUSC, 2002.

DIAS, E. F. Gramsci em Turim: a construção do conceito de hegemonia. São Paulo: Xamã, 2000.

DUSSEL, E.. 1492: o encobrimento do outro (a origem do mito da modernidade). Conferências de Frankfurt. Petrópolis, Vozes. 1992.

EVARISTO, C. Vozes-mulheres. Poemas de recordação e outros movimentos. Rio de Janeiro: Malê, 2017.

FEITOSA, A. C. Cultura e Sustentabilidade em foco: a Cultura da Sustentabilidade Ambiental. Rev. Interd. em Cult. e Soc., São Luís, v. 2, n. 2, p. 33-61, Jul./Dez. 2016.

FANON, F.. Os condenados da Terra. Juiz de Fora, UFJF. 2000.

FEITOSA, A. C.. Cultura e sustentabilidade em foco: a cultura da sustentabilidade ambiental. Rev. Interd. em Cult. e Soc. (RICS), São Luís, v. 2, n. 2, p. 33-61, jul./dez. 2016.

FERNANDES, J. A. B.; PEREIRA, C. S.; MELO, A. C.; KATO, D. S.; ALMEIDA, R. O. de. Pesquisa em Educação Ambiental e culturas no EPEA. Pesquisa em Educação Ambiental, Rio Claro, v. 13, n. 1, p. 154-166, 2018.

FERREIRA, N. S. A. As pesquisas denominadas "estado da arte". Educ. Soc., Campinas, v. 23, n. 79, p. 257-272, Ago. 2002.

FREIRE, P. Extensão ou comunicação? 7 ed. Rio de Janeiro: Paz e Terra, 1983.

FREIRE, P. Pedagogia do Oprimido. 17 ed. Rio de Janeiro: Paz e Terra, 1987.

FREIRE, P. Pedagogia da Esperança: um reencontro com a pedagogia do oprimido. 17 ed. São Paulo: Paz e Terra, 2011.

FREIRE; P., MACEDO, D.. Alfabetização: leitura da palavra leitura do mundo. Rio de Janeiro: Paz e Terra.1990.

GEERTZ, C. A interpretação das culturas. São Paulo: LTC, 1989.

GRAMSCI. A. Maquiavel: a Política e o Estado Moderno. São Paulo: Civilização Brasileira, 1982.

GUERRA, A. F. S.; GUIMARÃES, M. Educação ambiental no contexto escolar: questões levantadas no GDP. Pesquisa em Educação Ambiental, Ribeirão Preto, v. 2, n. 1, p. 155-167, Jan./Jun. 2007.

GUIDO, L. F. E. Apresentação das discussões do GDP Pesquisa em Educação Ambiental e Culturas. Apresentação em arquivo de formato digital (.ppt) exibida na sessão de discussão dos GDPs do VII Epea, realizado em Rio Claro (SP), de 7 a 10 de julho de 2013. 
HART, P.; NOLAN, K. A critical analysis of research in environmental education. Studies in Science Education, Leeds, v. 34, n. 1, p. 1-69, 1999.

HORKHEIMER, M.; ADORNO, T. W. Dialética do esclarecimento. Rio de Janeiro: Jorge Zahar, 1985.

KASSIADOU, A.; STORTTI, A.; SANCHEZ, C. Educação Ambiental desde El Sur. 1 ed. Atualizada. Macaé: NUPEM, 2018.

KASSIADOU, A.; STORTTI, A.; SANCHEZ, C. Educação ambiental desde el sur: Reflexões a partir do pensamento decolonial latino americano para construção de diálogos interculturais. In: I CONGRESSO INTERNACIONAL EPISTEMOLOGIAS DO SUL: PERSPECTIVAS CRÍTICAS, 1, 2016, Foz do Iguaçu. Anais... Foz do Iguaçu: UNILA, 2016. v. II, p. 176-183. Disponível em: https://plataforma9.com/congressos/icongresso-internacional-epistemologias-do-sul-perspectivas-criticas.htm. Acesso em: 30 de nov. de 2016.

LEFF, E.. Ecologia, capital e cultura. A territorialização da racionalidade ambiental. Petrópolis, Brasil. Editora Vozes. 2009.

LOUREIRO, C. F. B. Educação ambiental transformadora. In: Layrargues, P. P. (Coord.) Identidades da educação ambiental brasileira. Brasília: Ministério do Meio Ambiente, 2004. p. 65-84.

Loureiro, C. F. B. e Cossío, M. F. B. Um olhar sobre a educação ambiental nas escolas: considerações iniciais sobre os resultados do projeto "O que fazem as escolas que dizem que fazem educação ambiental". In: Mello, S. e Trajber, R. (orgs.) Vamos cuidar do Brasil: conceitos e práticas em educação ambiental. Brasília: MEC/UNESCO, 2007.

MELO, A. C. Biodiversidade: Narrativas, diálogos e entrelaçamento de saberes da comunidade/escola em um território quilombola do Semiárido Baiano. 2019. 216f. Tese (Doutorado em Ensino, Filosofia e História das Ciências) - Universidade Federal da Bahia/Universidade Estadual de Feira de Santana, Salvador, 2019.

MOORE, J. W. The Capitalocene. Part I: On the Nature \& Origins of Our Ecological Crisis. The Journal of Peasant Studie, Inglaterra, v. 44, n.3, p. 594-630, 2014. Disponível em: https://www.tandfonline.com/doi/abs/10.1080/03066150.2016.1235036. Acessado em 18 de nov. 2019.

RINK, J.; MEGID NETO, J. Tendências dos artigos apresentados nos Encontros de Pesquisa em Educação Ambiental (EPEA). Educ. rev., Belo Horizonte, v. 25, n. 3, p. 235-263, Dez. 2009. Disponível em: <http://www.scielo.br/pdf/edur/v25n3/12.pdf>. Acesso em: 27 mai. 2020.

SAID, Edward. Cultura e imperialismo. São Paulo: Companhia das Letras, 2011.

SANTOS, José Luiz dos. O que é cultura. Rio de Janeiro, Editora Brasiliense. 1987.

SANTOS, B. de S. Para além do pensamento abissal: das linhas globais a uma ecologia de saberes. Novos estud. - CEBRAP, São Paulo, n. 79, p. 71-94, 2007. Disponível em: https://www.scielo.br/scielo.php?script=sci_arttext\&pid=S0101-33002007000300004. Acessado em: 27 de maio de 2017.

WALSH, C. (Ed.). Pedagogías decoloniales: práticas insurgentes de resistir, (re)existir y (re)vivir. Tomo II. Quito: Ediciones Abya-Yala, 2017. 